\title{
Emergence of nontoxic mutants as revealed by single filament analysis in bloom-forming cyanobacteria of the genus Planktothrix
}

\author{
Qin Chen ${ }^{1,2}$, Guntram Christiansen², Li Deng ${ }^{2,3}$ and Rainer Kurmayer ${ }^{2^{*}}$
}

\begin{abstract}
Background: Bloom-forming cyanobacteria cause toxic algae outbreaks in lakes and reservoirs. We aimed to explore and quantify mutation events occurring within the large mcy gene cluster (55 kbp) encoding microcystin (MC) biosynthesis that inactivate $M C$ net production. For this purpose we developed a workflow to detect mutations in situ occurring anywhere within the large mcy gene cluster as amplified from one single filament of the red-pigmented cyanobacterium Planktothrix rubescens. From five lakes of the Alps eight hundred Planktothrix filaments were isolated and each individual filament was analyzed for mutations affecting the mcy genes.

Results: Mutations inactivating MC synthesis were either through an insertion element ISPIr1 or the partial deletion of mcy genes. Neutral mutations not affecting MC biosynthesis occurred within two intergenic spacer regions, either through the insertion of a Holliday-junction resolvase RusA or ISPIr1. Altogether, the insertions affected a few mcy genes only and their location was correlated with regions similar to repetitive extragenic palindromic DNA sequences (REPs). Taking all of the filaments together, the mutations leading to the inactivation of $M C$ synthesis were more rare (0.5-6.9\%), when compared with the neutral mutations (7.5-20.6\%). On a spatial-temporal scale the ratio of MC synthesis-inactivating vs. neutral mutations was variable, e.g., the filament abundance carrying partial deletion of mcyD (5.2-19.4\%) and/or mcyHA (0-7.3\%) exceeded the abundance of neutral mutations.

Conclusions: It is concluded that insertion events occurring within the Planktothrix mcy gene cluster are predictable due to their correlation with REPs. The frequency of occurrence of the REPs within the mcy gene cluster of Planktothrix relates to the rather common mutation of mcy genes in Planktothrix. Spatial-temporal variable conditions may favor the emergence of partial mcy deletion mutants in Planktothrix, in particular a higher proportion of genotypes resulting in inactivation of MC synthesis might be caused by increased ISPIr1 activity.
\end{abstract}

Keywords: cyanoHABs, Microcystin, Microevolution, Mobile elements, Single-colony PCR, in situ observation

\section{Background}

The filamentous, bloom-forming cyanobacterium Planktothrix, occurs in the pelagic zone of lakes and reservoirs, and is one of the main producers of microcystin (MC) - a hepatotoxin that poses a health threat to humans and livestock [1]. The blooming of Planktothrix regularly leads to toxic algae outbreaks, e.g., in December 2013 the water

\footnotetext{
* Correspondence: rainer.kurmayer@uibk.ac.at

${ }^{2}$ Research Institute for Limnology, University of Innsbruck, Mondseestrasse 9, 5310 Mondsee, Austria

Full list of author information is available at the end of the article
}

distributed in Užice in Serbia was banned for drinking and food preparation affecting thousands of people because of the intense bloom of toxic P. rubescens in Lake Vrutci, which served as the source of water supply. There is a documented history on these relatively sudden mass appearances of toxic $P$. rubescens, particularly in reservoirs [2-4], which is of relevance not at least due to their ongoing construction [5].

$\mathrm{MC}$ is synthesized by a nonribosomal peptide synthetase (NRPS) encoded by the $m c y$ gene cluster containing nine to ten genes that have been elucidated from three abundant 
MC-producing genera Microcystis, Planktothrix and Anabaena [6-8]. Planktothrix [9] and Anabaena [10] have been reported to contain mutations within the mcy gene cluster. In Planktothrix the mcy gene cluster is affected by (i) recombination events affecting enzymatic domains [11, 12], and (ii) by inactivation, e.g., due to the partial deletion of mcy genes [13] or the insertion of transposable elements [9]. The latter mutations that lead to nontoxic subpopulations have been found to cooccur with the toxic subpopulation in nature $[13,14]$. Individuals carrying mutations inactivating the $m c y$ genes could not be differentiated from those carrying the original $m c y$ gene cluster by phylogenetic analysis using housekeeping genes $[15,16]$. This result implies that the respective genotypes carrying those mutations in the $m c y$ gene cluster are evolutionary relatively young and/or possibly the selective pressure is not high enough to favor their phylogenetic fixation. Previously, the specific mutant $m c y$ genotypes were found to be distributed among twelve lakes of the Alps (Austria, Germany, Switzerland) and to occur consistently irrespective of the total population density [14]. Only recently, through an almost 30-year observation period, a gradual increase of one mcy mutant genotype carrying a $1.8 \mathrm{kbp}$ deletion of the $m c y$ gene cluster was discovered [17].

Currently, our understanding on the factors leading to the mutations within the mcy gene cluster is low, both with regard to molecular factors as well as the ecological factors influencing the activity of mutagenic elements such as transposases. In general, physiological stress conditions have been observed to favor transposase activity [18]. Since mutations often lead to the inactivation of MC synthesis, the emergence of nontoxic genotypes in Planktothrix populations would decrease the MC production, which is potentially relevant since $P$. rubescens populations have been described with the on average highest MC content in nature [19].

We aimed to develop a workflow to detect mutations in situ occurring within the large mcy gene cluster as amplified from one single P. rubescens filament. Such results can pave the way to understand the regulation of the occurrence of mutations, especially those inactivating $\mathrm{MC}$ synthesis. In addition several mutations within the $m c y$ gene cluster have been characterized previously using isolated clonal strains thus, enabling to differentiate between mutations resulting in inactivation of $\mathrm{MC}$ synthesis and neutral mutations not affecting MC synthesis $[9,11,13,14]$. Since the entire $m c y$ gene cluster spans $>55,000 \mathrm{bp}$, a sustainable technique is required that is able to amplify fragments covering the entire $m c y$ gene cluster. This would make it possible to analyze (i) a population for all mutations affecting MC synthesis in real-time, (ii) the phylogenetic divergence of those mutants when compared with genotypes still containing the original $m c y$ gene cluster using housekeeping genes, (iii) the abundance of each of the discovered mcy mutants on a spatial and temporal scale.

\section{Results}

Influence of filament length on PCR results

In total, 914 filaments of red-pigmented $P$. rubescens were isolated from five lakes in the Alps (Table 1) and analyzed for mutations affecting the $m c y$ genes (Fig. 1). Taking together all filaments, $87.5 \%$ (800 out of 914) showed a PCR product when amplifying the intergenic spacer region (IGS) between $p s a \mathrm{~A}$ and $p s a \mathrm{~B}$. A minimum of hundred positive filaments from each of the five populations were sampled.

Due to the observed variability in filament length (Table 1) it was important to know whether the shorter filaments contained sufficient DNA template for PCR. The minimum filament length $(88 \mu \mathrm{m})$ that was recorded corresponded to 29 cells (Additional file 1). Taking all filaments together, the filaments that were found PCR positive differed marginally in length (average $477 \pm 7 \mathrm{SE}$ ) from the filaments that were found PCR negative $(447 \pm 21)$, (Mann-Whitney Rank Sum Test, $p=0.04$, Student's $t$-test, $p=0.17$, Additional file 1 ). When comparing the proportion of PCR positive filaments between populations rather the opposite was observed, i.e., the on average longest filaments isolated from Lake Wörthersee showed the lowest proportion of PCR positive samples (73.5 \%). Thus the influence of DNA template amount on PCR result variability between populations was considered of minor importance.

\section{Mutations within the microcystin synthesis gene cluster}

All Planktothrix filaments that were found to be PCR positive also contained the $m c y$ gene cluster. An example for PCR amplification of the entire $m c y$ gene cluster from one single filament is shown in Fig. 2a. Sixteen primer pairs were used to amplify mcy gene fragments of $3.5 \mathrm{kbp}$ without interruption.

Among all of the filaments, $20 \%$ were indistinguishable from the reference $m c y$ gene cluster described from $P$. agardhii NIVA-CYA126/8 (Access No. AJ441056), while $80 \%$ showed polymorphisms in PCR product size (Fig. 2b, c). Among these, one smaller PCR product (59\%) was due to the functional recombination of the mcyAA1 adenylation domain, i.e., the replacement of the mcyA variant containing a gene of the N-methyltransferase at pos. 34,656 37,592 (AJ441056) by the shorter mcyA variant lacking the $\mathrm{N}$-methyltransferase as described [11].

Four different polymorphisms with increased amplicon size were located within the IGS of $m c y$ TD (20.6 \%), within $m c y \mathrm{D}(0.5 \%)$, within the IGS of $m c y \mathrm{EG}$ (7.5\%), and within $m c y \mathrm{~A}(0.6 \%)$, (Fig. 3a). The increase in amplicon size located between $m c y \mathrm{~T}$ and $m c y \mathrm{D}(1194 \mathrm{bp})$ at pos. 1294 of 
Table 1 Number of isolated Planktothrix rubescens filaments, percentage of PCR-positive filaments, and percentage of mutations

\begin{tabular}{|c|c|c|c|c|c|c|c|c|c|c|c|}
\hline & \multirow{3}{*}{$\begin{array}{l}\text { Filament } \\
\text { number }\end{array}$} & \multirow{3}{*}{$\begin{array}{l}\text { Positive } \\
\text { Entry } \\
\text { PCR (\%) }\end{array}$} & \multicolumn{2}{|c|}{ Characteristics of filaments } & \multicolumn{7}{|c|}{ Mutations within the mcy gene cluster (\%) } \\
\hline & & & \multirow{2}{*}{$\begin{array}{l}\text { Average (min, } \\
\text { max) length } \\
(\mu \mathrm{m})\end{array}$} & \multirow{2}{*}{$\begin{array}{l}\text { Average (min, } \\
\text { max) cell } \\
\text { number }^{a}\end{array}$} & \multicolumn{3}{|c|}{ MC synthesis not inactivated } & \multicolumn{4}{|c|}{ Inactivation of MC synthesis } \\
\hline & & & & & mcyTD insertion & mcyEG insertion & Short mcyA variant & mcyD insertion & mcyA insertion & mcyD deletion & mcyHA deletion \\
\hline \multicolumn{12}{|l|}{ Mondsee (AT) } \\
\hline Mar 2012 & 105 & 95.2 & $1356(484,2574)$ & $435(155,825)$ & 5.7 & 3.4 & 81.1 & 0 & 0 & 5.2 & 0 \\
\hline Jun 2012 & 108 & 92.6 & $1251(506,2222)$ & $401(162,712)$ & 2.0 & 2.0 & 67.7 & 2.0 & 1.0 & 7.2 & 3.0 \\
\hline Sep 2012 & 102 & 98 & $1653(990,2618)$ & $530(317,839)$ & 27.0 & 1.0 & 44.8 & 0 & 0 & 19.4 & 7.3 \\
\hline Apr 2013 & 107 & 93.4 & $1392(748,2354)$ & $446(240,754)$ & 13.1 & 0 & 53.3 & 1.0 & 0 & 18.0 & 7.1 \\
\hline \multicolumn{12}{|l|}{ Other lakes } \\
\hline Wörthersee (AT) & 136 & 73.5 & $2200(858,6600)$ & $705(275,2115)$ & 18.4 & 36.0 & 67.3 & 1.0 & 4.0 & 5.0 & 3.1 \\
\hline Zürichsee $(\mathrm{CH})$ & 121 & 82.6 & $1032(440,1738)$ & $331(141,557)$ & 25.3 & 9.0 & 45.0 & 0 & 0 & 1.0 & 1.0 \\
\hline Hallwilersee $(\mathrm{CH})$ & 120 & 83.3 & $1555(704,2772)$ & $498(226,888)$ & 42.6 & 5.3 & 82.4 & 0 & 0 & 0 & 0 \\
\hline Ammersee (DE) & 115 & 87 & $1444(638,2420)$ & $463(204,775)$ & 37.6 & 4.2 & 60.6 & 0 & 0 & 0 & 0 \\
\hline Total & 914 & 87.5 & $1479(440,6600)$ & $474(141,2115)$ & 20.6 & 7.5 & 59 & 0.5 & 0.6 & 6.9 & 2.6 \\
\hline
\end{tabular}

aestimated from linear regression curve (Additional file 1) 


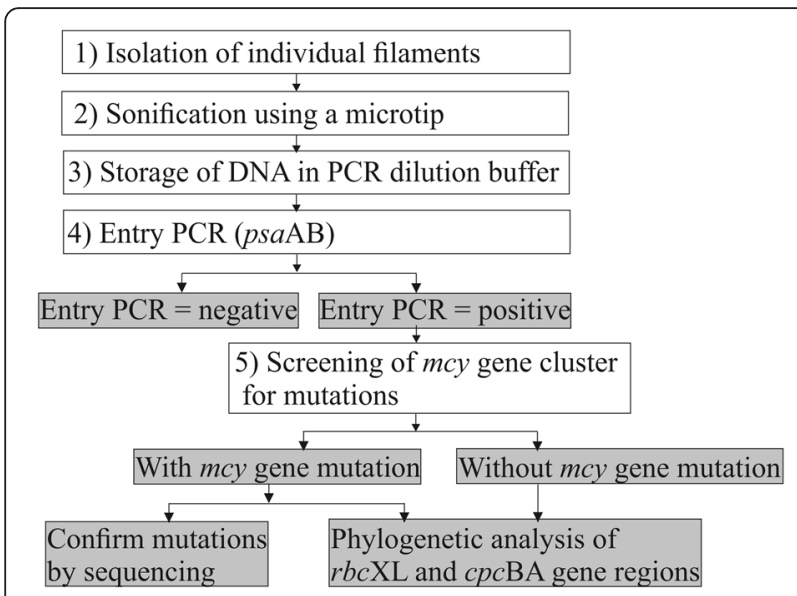

Fig. 1 Flow diagram showing steps of Planktothrix rubescens filament isolation and analysis (white boxes) and obtained results (grey boxes). For PCR conditions and primers see text and Additional file 6

the reference mcy gene cluster (AJ441056) was due to an inserted sequence coding for an ORF (pos. 997-742) homologous to crossover junction endodeoxyribonuclease RusA (85 aa, $100 \%$ similarity on the amino acid level, P. agardhii NIVA-CYA15, WP_027250107), and a second ORF (pos. 742-58) which was a hypothetical protein distantly related to archaeal Holliday junction resolvase, (227 aa, $100 \%$ similarity, P. agardhii NIVA-CYA15, WP_027250106). From the sequences obtained $(n=14)$ no variability of the insertion site could be found and only one orientation was observed. The other three insertions were caused by the IS element ISPlr1 (1423 bp), [14], i.e., within $m c y \mathrm{D}$ (at pos. 11,908 of the $m c y$ gene cluster, AJ441056), within the IGS of $m c y$ EG (at pos. 23,809), and within $m c y$ A (at pos. $41,274)$, of which the insertion site and the orientation were described previously [9].

Deletions were detected within mcyD (6.9 \%) and another deletion affected both $m c y \mathrm{H}$ and $m c y \mathrm{~A}(2.6 \%)$. The deletion within mcyD comprised 1665 bp (from pos. 2891 to 4555 of AJ441056), while the deletion occurring within mcyHA (1924 bp, from pos. 33,334 to 35,257 of the mcy gene cluster, AM990462.1) was described previously [9]. In summary, MC biosynthesis-inactivating mutations were observed only within a few genes $(m c y \mathrm{D}$, $\mathrm{H}, \mathrm{A}$ ), while the other six genes part of the $m c y$ gene cluster were not affected. For both housekeeping gene loci, $r b c \mathrm{XL}$ (seven genotypes, $n=64$ ) and $c p c \mathrm{BA}$ (nine genotypes, $n=58$ ), the one genotype representing the largest number of individuals ( $r b c \mathrm{XL}, n=50 ; c p c \mathrm{BA}, n=40$ ) was comprised both of individuals without mutations or either carrying insertions $(m c y \mathrm{D}, m c y \mathrm{TD}, m c y \mathrm{EG}$ or $m c y \mathrm{~A})$ or partial deletions (mcyD and $m c y \mathrm{HA})$, Table 2. Consequently, no phylogenetic diversification of specific $m c y$ mutation genotypes was observed.

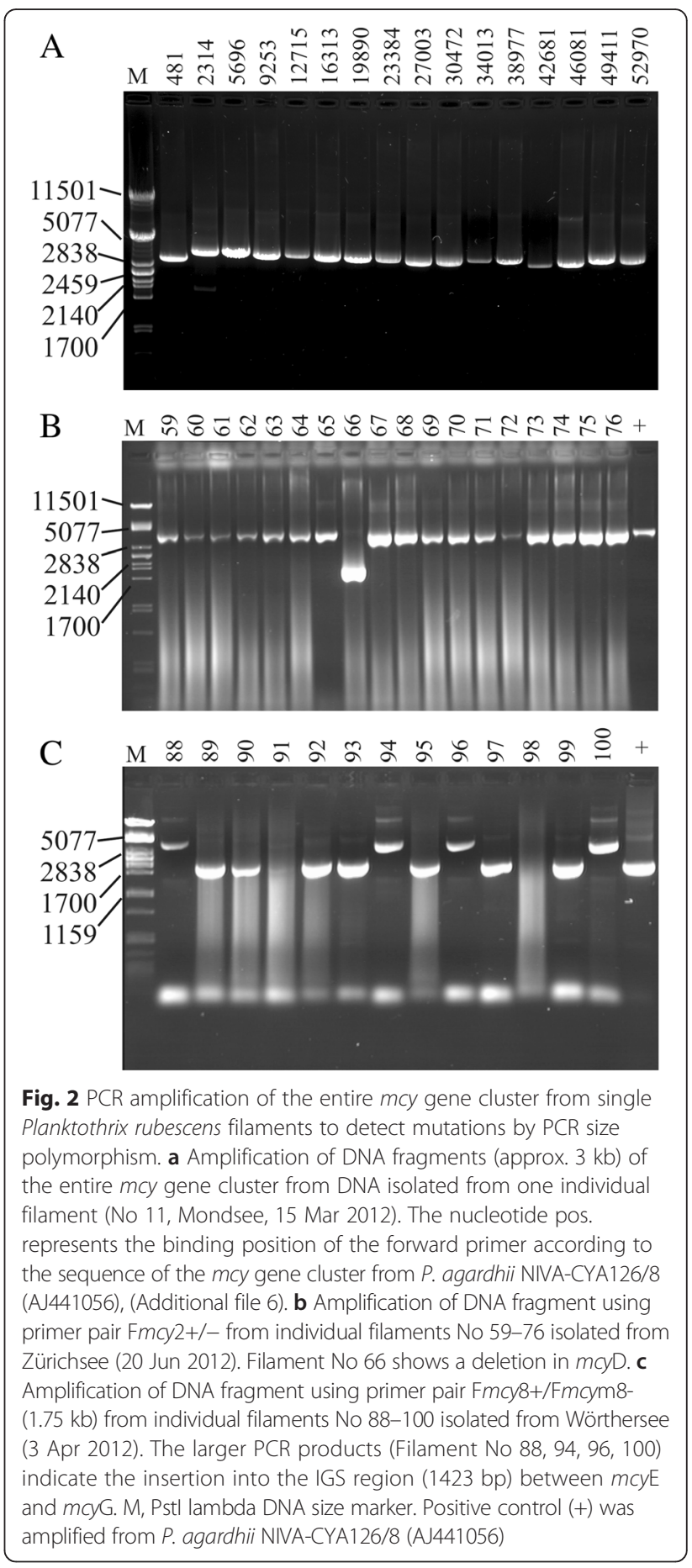

Direct repeats and repetitive sequences within mutations The sequencing of the ISPlr1 elements inserted into the $m c y$ gene cluster $(n=17)$ revealed identical inverted repeats (IRL: 5'-CAGGGCTGTTTCA -3' and IRR: 5'TGAAACAGCCCTG-3'). The ISPlr1 elements also showed similarity with regard to the direct repeat (DR) sequence (10 bp). In total, five DR sequences were found, i.e., for the $m c y \mathrm{D}$ gene (5'-CCCGTGCACG-3' or 


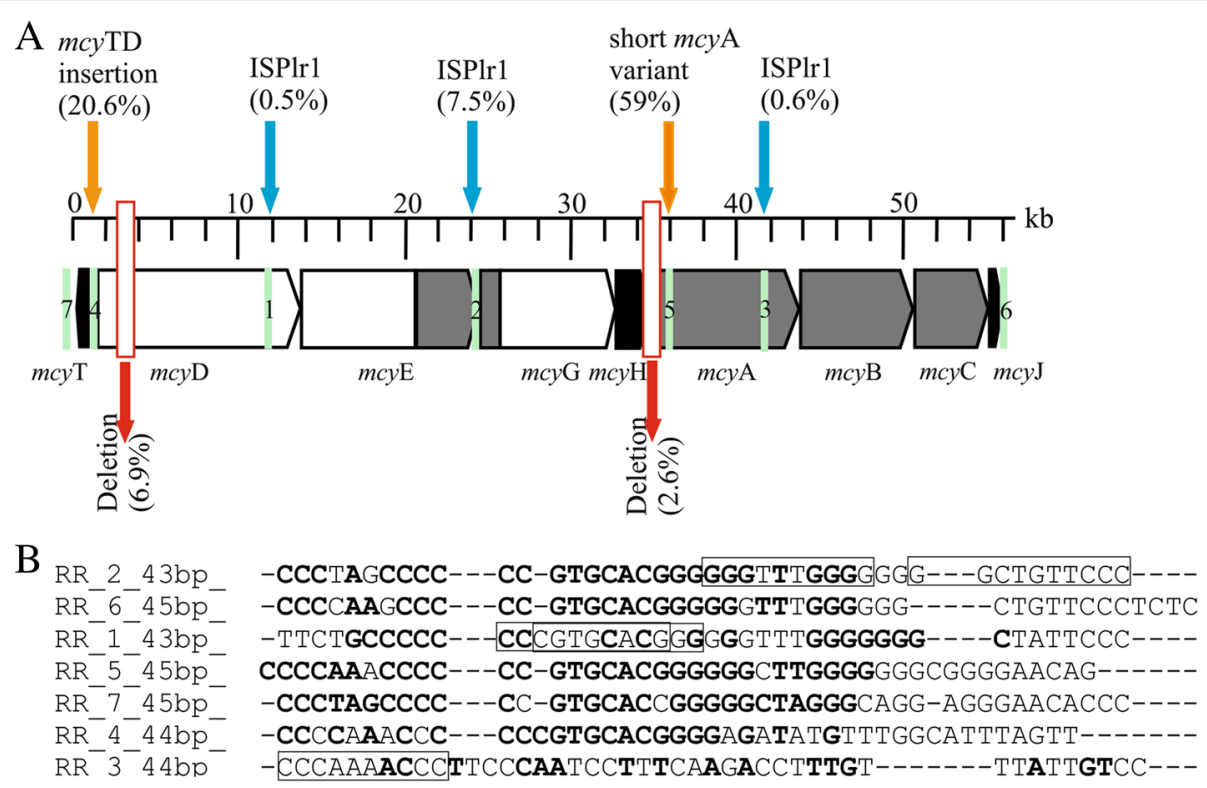

Fig. 3 a Schematic view of Planktothrix mcy gene cluster and location of mutations found in individual filaments and location of repetitive regions $1-7$ (in green). Taking all filaments together the relative frequency of each mutation is given in parentheses. ISPIr1, P. rubescens IS element containing the conserved DDE domain for DNA transposition [9]; b Alignment of repetitive sequence regions within the $P$. agardhii NIVA-CYA126/8 mcy gene cluster (ASAK00000000). The framed boxes indicate the short directly repeated sequences (DR) of 10 bp in length resulting in insertion of transposable element ISPIr1. Bold letters indicate palindromic sequences

$5^{\prime}$-CGTGCACGGG-3'), for the mcyEG-IGS region (5' GGGTTTGGGG-3' or 5'-GGCTGTTCCC-3'), and for the $m c y$ A gene $\left(5^{\prime}\right.$-CCCAAAACCC- $\left.3^{\prime}\right)$. Within the entire reference $m c y$ gene cluster of $P$. agardhii NIVACYA126/8 (AJ441056), seven GC rich repetitive regions (RRs), which were $43-45$ bp in length, were identified. These RRs contained the above mentioned DR sequences and were similar to the repetitive extragenic palindromic DNA sequences (REPs) described in Proteobacteria and Actinobacteria [20] and were predicted to form DNA stem-loop hybridization [21]. RR 1 (within $m c y \mathrm{D}$ ), RR 2 (within $m c y$ EG-IGS), and RR 3 (within $m c y \mathrm{~A}$ ), all showed insertion by ISPlr1. RR 4 was located at the $5^{\prime}$ end of the $m c y$ TD insertion (the putative resolvase), while RR 5 was located within the recombination leading to the short mcyA variant (Fig. 3). RR 6 was found $121 \mathrm{bp}$ downstream of $m c y$, and RR 7 was located 622 bp upstream of $m c y$ T. For RR 6 no mutation was observed (Additional file 2). The same IRR sequence of ISPlr1 (5'-TGAAACAGCCCTG-3') was also observed next to RR 7. In summary, within the Planktothrix mcy gene cluster the insertion of ISPlr1 elements was not randomly distributed but correlated with repetitive DNA described as REPs from bacteria in general.

\section{Abundance of mutations}

One fifth of the population ( $n=162,20 \%)$ did not show any detectable mutation in comparison with the reference mcy gene cluster (AJ441056). Most frequently, the filaments contained one mutation $(n=492,62 \%)$, while filaments carrying two mutations $(n=142,18 \%)$ or three mutations $(n=4,0.5 \%)$ were rare. In general, the recombination resulting in the short $m c y \mathrm{~A}$ variant constituted the dominant part of the population (45-82\%, Table 1). The second most abundant filament number was found to contain the mcyTD insertion ( $2-43 \%)$, while $0-36 \%$ carried the mcyEG insertion. Within IS element caused insertions, the number of ISPlr1 elements inserted into the IGS of $m c y$ EG exceeded the number of ISPlr1 elements inserted into $m c y \mathrm{D}$ or $m c y \mathrm{~A}$ considerably. Taking all filaments together, the mutations leading to the inactivation of $\mathrm{MC}$ synthesis were more rare $(0-7 \%)$, when compared with the abundance of the MC synthesis neutral mutations (7.5 - 20.6\%).

The filaments carrying either the long mcyA variant or the short mcyA variant contained a rather similar proportion of all the other mutations (Fig. 4). Only the mcyHA deletion $(0-7 \%)$ was perfectly linked to the mcyA short variant genotype. Filaments carrying a deletion in mcyHA $(n=21)$ also often had a deletion in $m c y \mathrm{D}(n=15)$. In contrast, filaments carrying the $m c y \mathrm{D}$ partial deletion $(n=55)$ were comprised not only of $m c y \mathrm{HA}$ deletion, but also of undeleted $m c y \mathrm{~A}$ short variant $(n=8)$ and long mcyA variant $(n=32)$. Of all the filaments carrying the mcyTD insertion $(n=165)$ only 6 filaments contained a second mutation (deletion in $m c y \mathrm{D}$, insertion into $m c y \mathrm{EG}, m c y \mathrm{HA}$ deletion, and insertion into $m c y \mathrm{~A})$. The filaments carrying the insertion of 
Table 2 Overview of sequences obtained from individual P. rubescens filaments during this study

\begin{tabular}{|c|c|c|c|}
\hline Locus & Title & Length (bp) & Access No. (Isolated filaments ${ }^{\mathrm{a}}$ ) \\
\hline mcyTD & $\begin{array}{l}\text { Crossover junction endodeoxyribonuclease RusA and } \\
\text { putative Holliday junction resolvase }\end{array}$ & 1194 & 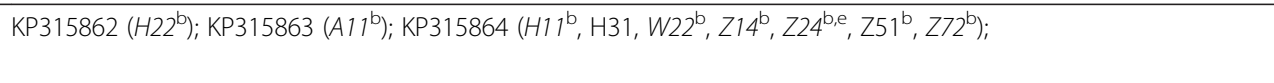 \\
\hline$r b c L X$ & $\begin{array}{l}\text { ribulose-1,5-bisphosphate carboxylase/oxygenase large } \\
\text { subunit ( } r b c \mathrm{~L}) \text { gene, and ribulose-1,5-bisphosphate } \\
\text { carboxylase/oxygenase (rbcX) gene }\end{array}$ & 383-390 & 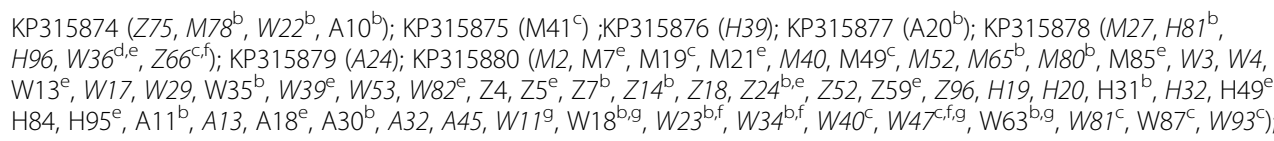 \\
\hline cpcBA & $\begin{array}{l}\text { partial } c p c B \text { gene for phycocyanin beta subunit and } \\
\text { partial } c p c A \text { gene for phycocyanin alpha subunit }\end{array}$ & 470 & 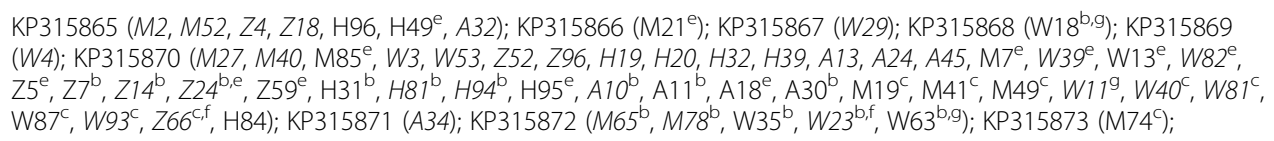 \\
\hline mcyD & partially deleted mcyD gene of the MC synthetase & 1964 & KP710231 (M14 $\left.{ }^{c}, M 19^{c}, M 41^{c}, M 74^{c}, W 40^{c}, W 47^{c, f, g}, W 49^{e}, W 81^{c}, W 87^{c}, W 93^{c}, Z 66^{c, f}\right)$ \\
\hline mcyA & $\begin{array}{l}\text { partial mcyA gene of MC synthetase, short mcyAA1 } \\
\text { variant, 5'end + } 3^{\prime} \text { end of recombination site }\end{array}$ & 447,428 & KP315861 (A16, A33, H9, H59, MNewSp6 ${ }^{\mathrm{b}}$, MNewSp92, W29, W98, Z21 $1^{\mathrm{b}}$, Z94) \\
\hline
\end{tabular}

The recombination of the short mcyA variant was indicated by italic font (M19, M41 and M74 was unkown), A Ammersee, $H$ Hallwilersee, $M$ Mondsee (March 2012), $W$ Wörthersee, $Z$ Zürichsee, MNewSp Mondsee (Apr 2013)

bfilament carrying mcyTD insertion; ${ }^{c} m c y D$ deletion; ${ }^{d} m c y D$ insertion; ${ }^{f} m c y E G$ insertion; ${ }^{e} m c y A$ insertion; ${ }^{9} m c y H A$ deletion 


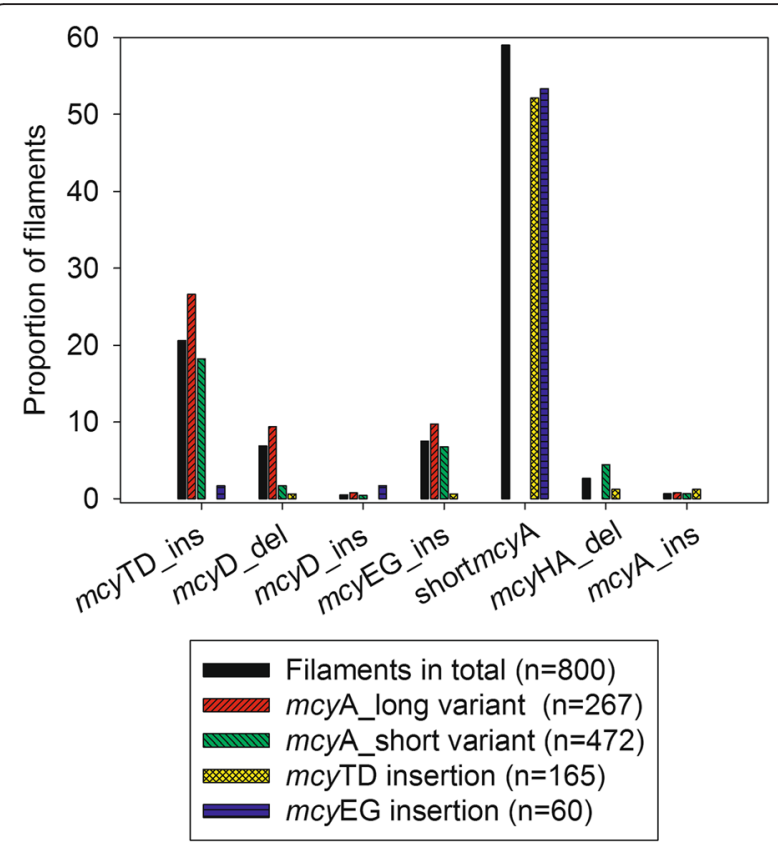

Fig. 4 Proportion of mcy gene cluster mutations found in the total Planktothrix population and in subpopulations. Relative frequency of various mcy gene cluster mutations in relation to the number of total filaments, the filaments carrying the long or short mcyA variant, the presence of the putative resolvase (inserted into the mcyTD-IGS) and the ISPIr1 inserted into mcyEG-IGS

mcyEG $(n=60)$ comprised only two filaments with another mutation (insertion of $m c y \mathrm{TD}$ and $m c y \mathrm{EG}$ ). Taking into account the probability that one filament carrying an insertion is hit by another insertion/deletion is quite low (only $18 \%$ of all filaments carried two mutations), the co-occurrence between $m c y \mathrm{HA}$ and $m c y \mathrm{D}$ deletions was considered remarkable.

When considering each population separately, the ratio of the proportion of neutral MC synthesis mutations vs. MC synthesis-inactivating mutations was more variable. Particularly, in Lake Mondsee, the number of $m c y \mathrm{D}$ and $m c y \mathrm{HA}$ deletions was equal to or exceeded the number of MC synthesis neutral mutations (Table 1). On average, the $m c y \mathrm{D}$ and $m c y \mathrm{HA}$ partial deletions were more abundant than $m c y \mathrm{D}$ and mcyA insertions. In contrast, in Lake Zürichsee, Hallwilersee, and Ammersee rather few mcy gene cluster mutations resulting in the inactivation of MC synthesis were observed. In summary, although the MC synthesis-inactivating mutations were never found to be dominant, spatial and seasonal variability in their proportion occurred.

\section{Discussion}

\section{Single filament genetics}

In this study, using the short-term sonification of filaments, large DNA fragments up to $6 \mathrm{kbp}$ were amplified from single filaments. Assuming a genome size of 5 mega base pairs and four chromosome copies per cell [22], it was calculated that the shortest filaments contained $2.8 \mathrm{pg}$ $(440 \mu \mathrm{m})$ and the longest filament $(6600 \mu \mathrm{m})$ contained $42 \mathrm{pg}$ of DNA resulting in 126-1890 mcy gene copies (Additional file 1). The influence of length variation among filaments on the PCR result variability was small, suggesting the DNA template amount to be of minor influence. Indeed, it was observed that longer filaments have a stronger tendency to stick to the walls of the reaction tube, and without immersion into PCR buffer they were lost from the PCR analysis. However, we cannot exclude a positive relationship between filament length and the proportion of PCR positive filaments if populations with on average shorter filaments $(<1000 \mu \mathrm{m})$ would have been included.

This study proposes an alternative method to metagenomics approaches with the aim to elucidate genetic variation on an individual basis. Since in general planktonic cyanobacteria grow clonal, resulting in the formation of macroscopic colonies or filaments, single isolated colonies and filaments can be considered a single genotype [23]. Walsby and co-workers were the first to use DNA obtained from heat-burst single filaments stored in PCR buffer and up to four different PCR amplifications of one or several gene loci were achieved [24]. So far, single colony/filament PCR techniques were applied to amplify relatively short DNA regions (a few hundreds of base pairs). In contrast, genomic approaches on the single cell level have revealed high genetic diversity within populations, e.g., of high-light adapted ecotypes of Prochlorococcus [25]. Since even within the cyanobacteria a significant cultivation bias toward a few genera exists, combining single colony isolation with more advanced molecular biological methods holds great potential to analyze the genetic and ecophysiological diversification of cyanobacteria at the individual level.

\section{Location of mcy gene cluster mutations}

All the mutations arising from insertions into the $m c y$ gene cluster were not randomly distributed but correlated with palindromic RRs of high genetic similarity (Fig. 3). The insertion of ISPlr1 was never found located outside such RRs, suggesting that the insertion of ISPlr1 depends on this type of inverted repeat sequence motif recognition that might be assisted by DNA stem-loop formation. Fewer et al. [10] described non-autonomous mobile miniature inverted-repeat transposable elements (MITEs) to insert into $m c y \mathrm{D}$ of Anabaena isolated from the Baltic Sea. In this study, the inverted RR observed for Planktothrix did not show the terminal inverted repeats that are typical for transposable elements [26]. Rather, these RR are similar to REPs that are characterized by a short stretch of high G-C content and have been associated with insertion of transposable elements in many 
bacteria previously [27]. For the cyanobacteria, REPs have long been used to aid taxonomic classification [28], but their role for genomic mutation and reorganization has been less explored. Notably, the short mcyA variant and rusA gene inserted into mcyTD also contained this $R R$, suggesting that the insertion of DNA fragments other than IS elements might be favored as well. The RR sequence reported in this study could not be found within $m c y$ gene clusters sequenced from other cyanobacteria, i.e., Anabaena strain 90 [8] or Nodularia [29] using standard BLASTn search algorithm. Only for Microcystis the short motif $5^{\prime}$-CCCCAAACCCC-3' occurred once within mcyE (strains PCC7806 and K-139, [6]; [30]) or twice in $m c y \mathrm{E}$ and $m c y \mathrm{D}$ (strain NIES 843, [31]). The absence of these Planktothrix specific RR in other cyanobacteria fits to the overall conclusion that the mcy gene cluster evolved from a cyanobacterial ancestor that occurred two billion years ago and then diversified according to the speciation of the different genera [32]. Consequently, the presence of these RR sequences within the mcy gene cluster of Planktothrix can explain why the insertion of transposable elements into mcy genes are the most common in Planktothrix populations and more rare for Microcystis and Anabaena [33].

\section{Emergence of the mcy gene cluster mutations}

In general, no congruency between phylogenetic diversification and a certain mutation was observed (Table 2). A straightforward explanation is that all of these mutations do not provide sufficient selective advantage to lead to their phylogenetic fixation. Still, the question remains as to why those mutants are maintained at relatively high frequency in nature. All of these mutations have been found distributed across the lakes of the Alps, and even the partial deletion of $m c y \mathrm{D}$ that has been discovered in this study has been detected in all study lakes (R.K. unpublished results). One possible explanation is that the same mutations emerge repeatedly and independently and die off regularly. This speculation is supported through the seasonal variation in abundance of the mutations in Lake Mondsee. It has been argued that the preservation of a certain ability of evolvability is of selective advantage for the total population that has been used as a kind of insurance of genome flexibility in unstable environments [34]. We have preliminary evidence that the activity of ISPlr1 also can be observed in vivo using the single filaments of Planktothrix strain No110 carrying ISPlr1 insertion within mcyD and mcyEG-IGS ([9]; C.Q., G.C., R.K. unpublished results). It is tempting to speculate that the varying abundance of MC synthesis mutations is based on variable ISPlr1 activity, which itself might be regulated by environmental conditions.

\section{Abundance of microcystin synthesis inactivating mutations} The mutations described from single filaments have also been found among isolated clonal strains ([9], R.K., unpublished results). Thus, mutations that inactivate MC synthesis could be differentiated from MC synthesis neutral mutations by strain analysis as described previously $[11,13]$. In particular strains carrying the mcyEG-IGS insertion (strains SAG6.89, CCAP1459/21, 1459/16, No31/1, 72, 82), as well as strains carrying the insertion between $m c y \mathrm{~T}$ and $m c y \mathrm{D}$ (CCAP1459/24, No21/2, 64, 241), all produce MC [35]. In contrast strains carrying the ISPlr1 insertion in $m c y \mathrm{D}$ (No110, 139, 145, 161, 166, 169, 170, 178) or mcyA (No40), and strains with a partial deletion of $m c y$ HA $(\mathrm{No62}, 65)$ or $m c y \mathrm{D}$ (No130, 137, 194) did not produce MC $[9,13,35]$. Taking all of the filaments together, the number of ISPlr1 inserted into mcyEG-IGS exceeded the number of ISPlr1 by far that was inserted directly into mcyA or mcyD. Since the former does not lead to the inactivation of MC synthesis, while the latter does, it might be speculated that selective pressure is preventing a high frequency of inactive mcy genotypes. Frequency-dependent selective pressure has been reported for the coexistence of genotypes in Pseudomonads either carrying plasmids providing mercury detoxification or plasmids free of mercury detoxification genes at a certain range of mercury concentration [36]. Taking into account that MC provides protection against grazers and parasites [37], such frequency dependent selective pressure would be a reasonable scenario that keeps functional $m c y$ genotypes as the dominant part of the Planktothrix sp. population in Lake Mondsee since its first observation in 2002 [13].

On the other hand, among the population from Lake Mondsee, the number of $m c y \mathrm{D}$ and $m c y \mathrm{HA}$ deletions outweighed the number of mcyEG-IGS ISPlr1 genotypes at least at two sampling dates. At present, it is not known as to whether the imprecise excision of ISPlr1 can cause the partial deletions observed within $m c y \mathrm{D}$ and $m c y \mathrm{HA}$. For many years, transposons Tn5, Tn7, Tn10 and bacteriophage Mu have been described to excise imprecisely from their point of insertion with the concomitant creation of deletions [38]. Among the 55 filaments carrying the partial deletion of $m c y \mathrm{D}$, none carried an insertion of ISPlr1 into $m c y \mathrm{D}$. In contrast, the partial deletion of $m c y \mathrm{HA}$ was only observed subsequent to the recombination of the short $m c y \mathrm{~A}$ variant. This mcyA short variant, however, carried the same RR sequence as has been found at the ISPlr1 insertion sites, and it seems possible that an imprecise excision of ISPlr1 finally leads to both partial deletions in $m c y \mathrm{D}$ and mcyA. Accordingly, Vasas et al. [39] reported the occurrence of a partial deletion within the mcyEG-IGS region of a $P$. rubescens strain isolated from a gravel pit pond in Hungary. In the future, more quantitative data 
will be needed to find out whether short-term shifts in the abundance of mutations occur and what the factors are that are leading to it.

\section{Conclusions}

By observing recombination processes within the mcy gene cluster of hundreds of single filaments in real-time, we conclude that insertion events occurring within the mcy gene cluster of Planktothrix are predictable due to the dependence on repetitive nucleotide sequence motifs, which represent REPs that are described as IS element insertion sites from other bacterial phyla. The higher abundance of those REPs within the mcy gene cluster of Planktothrix but not in other genera Microcystis and Anabaena can explain the more frequent mutation of the mcy gene cluster in Planktothrix when compared with other genera. Although the MC synthesis inactive genotypes were not observed to be dominant, we found evidence that under certain conditions a higher proportion of MC synthesis inactive mcy genotypes occurred, which might be caused by the increased activity of ISPlr1.

\section{Methods}

\section{Study area and sampling}

Five lakes located in the Alps, Mondsee $\left(47^{\circ} 49^{\prime} \mathrm{N}, 13^{\circ} 22^{\prime} \mathrm{E}\right)$, Wörthersee $\left(46^{\circ} 37^{\prime} \mathrm{N}, 14^{\circ} 07^{\prime} \mathrm{E}\right)$, Zürichsee $\left(47^{\circ} 15^{\prime} \mathrm{N}, 08^{\circ} 38^{\prime}\right.$ E), Hallwilersee $\left(47^{\circ} 17^{\prime} \mathrm{N}, 08^{\circ} 12^{\prime} \mathrm{E}\right)$, Ammersee $\left(47^{\circ} 59^{\prime} \mathrm{N}\right.$, $\left.11^{\circ} 07^{\prime} \mathrm{E}\right)$ were sampled for red-pigmented $P$. rubescens filaments by pulling a plankton net ( $30 \mu \mathrm{m}$ mesh size) from a depth of $20 \mathrm{~m}$ to the surface from a boat in the middle of the lake (Table 1). The lakes are deep, physically stratified, and have been shown to inhabit red-pigmented Planktothrix during the summer either seasonally (Ammersee) or perennially (Mondsee, Wörthersee, Zürichsee, Hallwilersee). No specific permissions were required for these locations/activities, as in all three countries (Austria, Germany, Switzerland) water quality analyses are free of permission in public waterbodies. In addition the field study did not involve endangered species.

\section{Filament isolation}

Individual $P$. rubescens filaments were picked randomly from diluted samples under a dissecting microscope as described [13]. Each filament was washed three times by subsequent transfers between drops of BG11 medium [40], measured in length and finally transferred to a $0.5 \mathrm{ml}$ Eppendorf tube containing $10 \mu \mathrm{l}$ of sterile Millipore water and stored at $-20{ }^{\circ} \mathrm{C}$.

\section{DNA extraction}

Single Planktothrix filaments were ultrasonified using a sonifier cell disruptor equipped with a microtip (Branson, Danbury, Connecticut, USA) under optimized conditions (see Additional file 3). The microtip was washed with $10 \%$ (v/v) $\mathrm{H}_{2} \mathrm{O}_{2}$ between individual samples. The quality of the obtained DNA fragments was tested with an Agilent Bioanalyzer 2100 (Agilent Technologies, Palo Alto, CA) following manufacturer's instructions. In a pilot experiment filaments were isolated from $P$. rubescens strain No3 and were sonified in different concentrations of 100, 50 and 10 filaments $\mu^{-1}$ (in $10 \mu \mathrm{l}, 15 \%$ ultrasound strength, $1 \mathrm{~s}$ ) to analyze the fragment size distribution of the obtained DNA. Independent from filament concentration a major peak of DNA elution was observed at $6000 \mathrm{bp}$, indicating that DNA templates of appropriate size for subsequent PCR amplification were available. As expected, DNA concentration and height of the major peak increased linearly with the number of sonified filaments (Additional file 3 ). In addition, the variable intensity of sonification $(10,15,20,25,30,35$ and $40 \%$ of total output, 100 filaments in $10 \mu \mathrm{l}, 1 \mathrm{~s}$ ) revealed an overall increase in DNA concentration. In contrast, the size of the DNA and the major peak height decreased indicating the increased fragmentation of the DNA (Additional file 3). Analogously, the DNA concentration increased with longer sonification time $(1,20,30,90,180,270$ and $450 \mathrm{~s}, 100$ filaments, in $100 \mu \mathrm{l}, 15 \%$ ultrasound strength), (Additional file 3). However, both DNA size and the major peak height decreased suggesting that DNA became increasingly fragmented with sonification time. Thus, in order to guarantee maximum DNA size, a low sonification intensity (15\%) and a short sonification time (1 s) were used during further analyses.

\section{DNA storage time}

To analyze the storage time of extracted DNA isolated from individual filaments, DNA was both stored at $-20{ }^{\circ} \mathrm{C}$ in Millipore water and in Phire Hot Start Polymerase Plant PCR dilution buffer (Finnzymes, Espoo, Finland). No PCR products were obtained from DNA extracted from filaments stored in Millipore water for more than two days (Additional file 4). In contrast, DNA extracted from filaments but stored in PCR dilution buffer consistently revealed PCR products during a storage time until 9 months (data not shown). Consequently, DNA stored in PCR dilution buffer was used for all further application.

In general, 16 primer pairs (Fmcyamplify fragments of $3.5 \mathrm{kbp}$ of the mcy gene cluster without interruption (see below). Pilot tests showed that using the Phire Hot start II DNA polymerase (Finnzymes, Espoo, Finland) following manufacturer's instructions, PCR products ranging from $500 \mathrm{bp}$ to $9 \mathrm{kbp}$ could be obtained from one single filament. In order to determine the maximum of PCR assays possible for each filament sample, DNA extracted from individual filaments was diluted with Phire Hot Start Polymerase 
PCR buffer 1-, 2-, 4-, 8-, and 16-fold. Using both the PC-IGS and 16S rDNA primer pairs (see below), PCR amplification was achieved until 16-fold dilution (Additional file 5).

\section{PCR amplification}

In order to confirm the presence of Planktothrix DNA after the sonification of each individual filament, the IGS between $p s a \mathrm{~A}$ and $p s a \mathrm{~B}$ was amplified (Additional file 6). The PCR was performed using Dream Taq polymerase (Thermo Scientific, Fermentas, St. Leon Rot, Germany) in $10 \mu \mathrm{l}$, containing $1 \mu \mathrm{l}$ of Dream Taq PCR buffer (10x), $0.4 \mu \mathrm{l}$ of $\mathrm{MgCl}_{2}(50 \mathrm{mM}), 0.3 \mu \mathrm{l}$ of dNTPs (10 mM each), $0.3 \mu \mathrm{l}$ of each primer (10 pmol $\mu \mathrm{l}^{-1}$ ), $0.05 \mu \mathrm{l}$ of polymerase, $6.65 \mu \mathrm{l}$ sterile Millipore water and $1.0 \mu \mathrm{l}$ DNA template. The PCR thermal cycling protocol included an initial denaturation step at $94{ }^{\circ} \mathrm{C}$ for $3 \mathrm{~min}$, followed by 35 cycles (denaturation at $94{ }^{\circ} \mathrm{C}$ for $30 \mathrm{~s}$, annealing at $60{ }^{\circ} \mathrm{C}$ for $30 \mathrm{~s}$, elongation at $72{ }^{\circ} \mathrm{C}$ for $30 \mathrm{~s}$ ), and a final elongation step at $72{ }^{\circ} \mathrm{C}$ for $1 \mathrm{~min}$.

In order to detect all the potential deletions and insertions within the entire $m c y$ gene cluster, 16 primer pairs (Fmcy1 - 16) were designed and used to amplify fragments of $3.5 \mathrm{kbp}$ without interruption (Additional file 6). Individual filament DNA samples were diluted 5 -fold resulting in $50 \mu \mathrm{l}$ of DNA template per filament in total. The PCR amplifications were performed in reaction mixtures of $10 \mu \mathrm{l}$, containing $2 \mu \mathrm{l}$ of PCR reaction buffer (5x), $0.2 \mu \mathrm{l}$ of dNTPs (Kapa Biosystems, Woburn, MA, USA), $0.5 \mu \mathrm{l}$ of each primer $\left(10 \mathrm{pmol} \mu \mathrm{l}^{-1}\right), 0.2 \mu \mathrm{l}$ of Phire Hot start II DNA polymerase, $5.6 \mu \mathrm{l}$ sterile Millipore water and $1 \mu \mathrm{l}$ DNA template. The PCR thermal cycling protocol included an initial denaturation step at $98{ }^{\circ} \mathrm{C}$ for $30 \mathrm{~s}$, followed by 40 cycles (denaturation at $98{ }^{\circ} \mathrm{C}$ for $5 \mathrm{~s}$, annealing at $60{ }^{\circ} \mathrm{C}$ for $20 \mathrm{~s}$, elongation at $72{ }^{\circ} \mathrm{C}$ for $\left.70 \mathrm{~s}\right)$ and final elongation $\left(72{ }^{\circ} \mathrm{C}, 1 \mathrm{~min}\right)$. The mutations were detected via the size difference of the PCR products during ethidium bromide stained gel electrophoresis as compared to the PCR products obtained from the reference strain $P$. agardhii NIVA-CYA126/8 (AJ441056) [7]. If no PCR product was obtained, shorter PCR products ( $1.75 \mathrm{kbp}, 35 \mathrm{~s}$ annealing) were amplified by combining a primer from the set Fmcy1 - 16 with the corresponding primer from the set Fmcym1 - 16 (Additional file 6), which were located in the middle of each $3.5 \mathrm{kbp}$ fragment. In order to identify insertions (i.e., the $m c y \mathrm{TD}$ insertion and $m c y \mathrm{EG}$ insertion), specific primer pairs were used, which consisted of one primer binding to a locus within the mcy gene cluster and the second primer binding to a locus within the insert. For the sequencing of selected PCR products, gene fragments were amplified using the $3{ }^{\prime}-5$ 'exonuclease-containing Phusion polymerase (Finnzymes, Espoo, Finland). The
PCR amplifications were performed in reaction mixtures of $25 \mu \mathrm{l}$, containing $5 \mu \mathrm{l}$ of Phusion GC reaction buffer, $0.5 \mu \mathrm{l}$ of dNTPs (10 mM of each, Kapa), $1.25 \mu \mathrm{l}$ of each primer $\left(10 \mathrm{pmol}_{\mu} \mathrm{l}^{-1}\right), 0.25 \mu \mathrm{l}$ of Phusion DNA polymerase, $15.8 \mu \mathrm{l}$ sterile Millipore water and $1 \mu \mathrm{l}$ DNA template. The PCR thermal cycling protocol was identical to the Phire Hot start II DNA polymerase.

\section{Phylogenetic analysis}

In order to assign individual filaments to Planktothrix phylogenetic groups, the IGS of $c p c \mathrm{BA}$ (the intergenic spacer region between phycocyanin $\mathrm{B}$ and phycocyanin A protein) and $r b c \mathrm{LX}$ (the intergenic spacer region between the large subunit of the ribulose bisphosphate carboxylase/ oxygenase and $r b c \mathrm{X}$ ) were amplified and sequenced (Additional file 6). The oligonucleotides used to amplify the $c p c \mathrm{BA}$ and $r b c \mathrm{LX}$ locus were designed previously [13], [16]. The PCR thermal cycling protocol included an initial denaturation step at $98^{\circ} \mathrm{C}$ for $30 \mathrm{~s}$, followed by 40 cycles $\left(98^{\circ} \mathrm{C}\right.$ for $5 \mathrm{~s}, 66^{\circ} \mathrm{C}$ for $20 \mathrm{~s}, 72^{\circ} \mathrm{C}$ for $30 \mathrm{~s})$ and final elongation $\left(72{ }^{\circ} \mathrm{C}, 1 \mathrm{~min}\right)$. PCR products were purified and sequenced by standard automated fluorescence techniques (Applied Biosystems, Weiterstadt, Germany). All sequence data have been submitted to the DDBJ/EMBL/GenBank databases under accession numbers KP315865 - 73 (cpcBA, 475 bp), KP315874 - 80 ( $r b c \mathrm{LX}, 390$ bp), KP315862 - 64 (the insertion into the intergenic region of mcyTD, $1194 \mathrm{bp}$ ), KP315861 (the flanking region of the inserted short $m c y A$ variant, 447 and $428 \mathrm{bp}$ ), KP710231 (the partial deletion of $m c y \mathrm{D}, 1964 \mathrm{bp}$ ), (Table 2).

\section{Availability of supporting data}

For nucleotide acid sequences submitted to the DDBJ/ EMBL/GenBank databases under accession numbers KP315861-80, KP710231 see text. The data supporting the results of this article are included in Additional files $1,2,3,4,5,6$ and 7.

\section{Additional files}

Additional file 1: Relationship between Planktothrix filament length and cell number and length of Planktothrix filaments as compared between samples found PCR negative or PCR positive. (DOCX $17 \mathrm{~kb}$ )

Additional file 2: Summary of repetitive regions (RR) and associated mutations through ISPIr1 and RusA occurring within the Planktothrix mcy gene cluster. (DOCX $13 \mathrm{~kb}$ )

Additional file 3: Measures of genomic DNA isolated from Planktothrix filaments using a cell disruptor sonifier. (DOCX $21 \mathrm{~kb}$ )

Additional file 4: Effect of storage time $\left(-20^{\circ} \mathrm{C}\right)$ of DNA extracted from sonified Planktothrix filaments in Millipore water on PCR amplification of the PC-IGS region. (DOCX $766 \mathrm{~kb}$ )

Additional file 5: Amplification of PCR products from DNA extracted from one single Planktothrix filament and diluted 1-, 2-, 4-, 8-, and 16fold. (DOCX $916 \mathrm{~kb}$ ) 
Additional file 6: Oligonucleotides used in the present study. (DOCX $19 \mathrm{~kb})$

Additional file 7: Occurrence of mutations in individual Planktothrix filaments (Excel spreadsheet). (XLSX $74 \mathrm{~kb}$ )

\section{Abbreviations}

MC: Microcystin; REPs: repetitive extragenic palindromic DNA sequences; NRPS: nonribosomal peptide synthetase; IGS: intergenic spacer region; IS element: Insertion sequence element; ISPIr1: IS element in P. rubescens; IRL: IRR, inverse repeat left, inverse repeat right; DR: direct repeat; RRs: GC rich repetitive regions; MITE: non-autonomous mobile miniature inverted-repeat transposable element.

\section{Competing interests}

The authors declare that they have no competing interests.

\section{Authors' contributions}

CQ, GC and RK carried out the molecular genetic studies, RK and LD participated in the design of the study and performed the statistical and sequence analysis. CQ, LD and RK have drafted the manuscript and RK, GC revised the manuscript. All authors read and approved the final manuscript.

\section{Authors' information}

This article is constituting part of the written thesis of CQ in order to fulfill the requirements for the PhD granted by the Northwest A \& F University, Yangling, Shaanxi Province, P.R. China.

\section{Acknowledgements}

Katharina Moosbrugger and members of the RK research group and colleagues at the Institute in Mondsee are gratefully acknowledged. We are grateful to Judith Blom (University of Zürich) and Arno Stöckli (Kanton Aargau) for providing samples. We would also like to thank Dong Qu (Northwest A \& F University, Shaanxi Province, P.R. China) for the support provided. This study was supported by the Austrian Science Fund (FWF), (P24070) to RK and the China Scholarship Council to QC. This paper is a contribution to the European Cooperation in Science and Technology, COST Action ES 1105 "CYANOCOST - Cyanobacterial blooms and toxins in water resources: Occurrence, impacts, and management".

\section{Author details}

${ }^{1}$ College of Natural Resources and Environment, Northwest A \& F University, Taicheng Road 3, 712100 Yangling, Shaanxi Province, P. R. China. ${ }^{2}$ Research Institute for Limnology, University of Innsbruck, Mondseestrasse 9, 5310 Mondsee, Austria. ${ }^{3}$ Helmholtz Zentrum München, Institute of Groundwater Ecology, Ingolstädter Landstrasse 1, 85764 Neuherberg, Germany.

Received: 5 June 2015 Accepted: 13 February 2016

Published online: 25 February 2016

\section{References}

1. WHO: Guidelines for drinking-water quality. First addendum to third edition 3rd edition, vol. 1, recommendations. Geneva, Switzerland: World Health Organization; 2006:515.

2. Almodovar A, Nicola GG, Nuevo M. Effects of a bloom of Planktothrix rubescens on the fish community of a Spanish reservoir. Limnetica. 2004;23(1-2):167-78.

3. Paulino S, Valerio E, Faria N, Fastner J, Welker M, Tenreiro R, et al. Detection of Planktothrix rubescens (Cyanobacteria) associated with microcystin production in a freshwater reservoir. Hydrobiologia. 2009;621(1):207-11.

4. Naselli-Flores L, Barone R, Chorus I, Kurmayer R. Toxic cyanobacterial blooms under a semiarid mediterranean climate: The magnification of a problem. Environ Toxicol. 2007;22(4):399-404

5. Padisák J, Vasas G, Borics G. Phycogeography of freshwater phytoplankton: traditional knowledge and new molecular tools. Hydrobiologia. 2016;764(1):3-27.

6. Tillett D, Dittmann E, Erhard M, von Döhren H, Börner T, Neilan BA. Structural organization of microcystin biosynthesis in Microcystis aeruginosa PCC7806: an integrated peptide-polyketide synthetase system. Chem Biol. 2000;7(10):753-64.

7. Christiansen G, Fastner J, Erhard M, Börner T, Dittmann E. Microcystin biosynthesis in Planktothrix: genes, evolution, and manipulation. J Bacteriol. 2003;185(2):564-72.
8. Rouhiainen L, Vakkilainen T, Siemer BL, Buikema W, Haselkorn R, Sivonen K. Genes coding for hepatotoxic heptapeptides (microcystins) in the cyanobacterium Anabaena strain 90. Appl Environ Microbiol. 2004;70(2):686-92.

9. Christiansen G, Kurmayer R, Liu Q, Börner T. Transposons inactivate biosynthesis of the nonribosomal peptide microcystin in naturally occurring Planktothrix spp. Appl Environ Microbiol. 2006;72(1):117-23.

10. Fewer DP, Halinen K, Sipari H, Bernardová K, Mänttäri M, Eronen $E$, et al. Non-autonomous transposable elements associated with inactivation of microcystin gene clusters in strains of the genus Anabaena isolated from the Baltic Sea. Environ Microbiol Rep. 2011;3(2):189-94.

11. Kurmayer R, Christiansen G, Gumpenberger M, Fastner J. Genetic identification of microcystin ecotypes in toxic cyanobacteria of the genus Planktothrix. Microbiol. 2005:151(5):1525-33.

12. Christiansen G, Yoshida W, Blom J, Portmann C, Gademann K, Hemscheidt T, et al. Isolation and structure determination of two microcystins and sequence comparisons of McyABC adenylation domains in Planktothrix species. J Nat Prod. 2008;71(11):1881-6.

13. Kurmayer R, Christiansen G, Fastner J, Börner T. Abundance of active and inactive microcystin genotypes in populations of the toxic cyanobacterium Planktothrix spp. Environ Microbiol. 2004;6(8):831-41.

14. Ostermaier $\mathrm{V}$, Kurmayer R. Distribution and abundance of nontoxic mutants of cyanobacteria in lakes of the Alps. Microb Ecol. 2009;58(2):323-33.

15. Christiansen G, Molitor C, Philmus B, Kurmayer R. Nontoxic strains of cyanobacteria are the result of major gene deletion events induced by a transposable element. Mol Biol Evol. 2008;25(8):1695-704.

16. Kurmayer R, Blom JF, Deng L, Pernthaler J. Integrating phylogeny, geographic niche partitioning and secondary metabolite synthesis in bloom-forming Planktothrix. ISME J. 2014;9(4):909-21.

17. Ostermaier V, Christiansen G, Schanz F, Kurmayer R. Genetic variability of microcystin biosynthesis genes in Planktothrix as elucidated from samples preserved by heat desiccation during three decades. PLoS One. 2013:8(11):e80177.

18. Shapiro JA. Transposable elements as the key to a 21st century view of evolution. Genetica. 1999;107(1-3):171-9.

19. Fastner J, Neumann U, Wirsing B, Weckesser J, Wiedner C, Nixdorf B, et al. Microcystins (hepatotoxic heptapeptides) in German fresh water bodies. Environ Toxicol. 1999;14(1):13-22

20. Tobes $\mathrm{R}$, Ramos JL. REP code: defining bacterial identity in extragenic space. Environ Microbiol. 2005;7(2):225-8.

21. Reuter J, Mathews D. RNAstructure: software for RNA secondary structure prediction and analysis. BMC Bioinformatics. 2010;11(1):129.

22. Christiansen G, Goesmann A, Kurmayer R. Elucidation of insertion elements carried on plasmids and in vitro construction of shuttle vectors from the toxic cyanobacterium Planktothrix. Appl Environ Microbiol. 2014;80(16):4887-97.

23. Hayes PK, Barker GLA, Batley J, Beard SJ, Handley BA, Vacharapiyasophon P, et al. Genetic diversity within populations of cyanobacteria assessed by analysis of single filaments. Antonie Van Leeuwenhoek. 2002;81:197-202.

24. Beard SJ, Handley BA, Hayes PK, Walsby AE. The diversity of gas vesicle genes in Planktothrix rubescens from Lake Zürich. Microbiol. 1999:145:2757-68.

25. Kashtan N, Roggensack SE, Rodrigue S, Thompson JW, Biller SJ, Coe A, et al. Single-cell genomics reveals hundreds of coexisting subpopulations in wild Prochlorococcus. Science. 2014;344(6182):416-20.

26. Delihas N. Impact of small repeat sequences on bacterial genome evolution. Genome Biol Evol. 2011;3:959-73.

27. Tobes R, Pareja E. Bacterial repetitive extragenic palindromic sequences are DNA targets for insertion sequence elements. BMC Genomics. 2006;7(1):62.

28. Smith JK, Parry JD, Day JG, Smith RJ. A PCR technique based on the HIP1 interspersed repetitive sequence distinguishes cyanobacterial species and strains. Microbiol. 1998;144(10):2791-801.

29. Moffitt MC, Neilan BA. Characterization of the nodularin synthetase gene cluster and proposed theory of the evolution of cyanobacterial hepatotoxins. Appl Environ Microbiol. 2004;70(11):6353-62.

30. Nishizawa T, Ueda A, Asayama M, Fujii K, Harada K, Ochi K, et al. Polyketide synthase gene coupled to the peptide synthetase module involved in the biosynthesis of the cyclic heptapeptide microcystin. J Biochem. 2000;127(5):779-89.

31. Kaneko T, Nakajima N, Okamoto S, Suzuki I, Tanabe Y, Tamaoki M, et al. Complete genomic structure of the bloom-forming toxic cyanobacterium Microcystis aeruginosa NIES-843. DNA Res. 2007;14(6):247-56.

32. Rantala A, Fewer DP, Hisbergues M, Rouhiainen L, Vaitomaa J, Börner T, et al. Phylogenetic evidence for the early evolution of microcystin synthesis. Proc Natl Acad Sci U S A. 2004;101(2):568-73. 
33. Dittmann E, Fewer DP, Neilan BA. Cyanobacterial toxins: biosynthetic routes and evolutionary roots. FEMS Microbiol Rev. 2013;37(1):23-43.

34. Heuer H, Abdo Z, Smalla K. Patchy distribution of flexible genetic elements in bacterial populations mediates robustness to environmental uncertainty. FEMS Microbiol Ecol. 2008;65(3):361-71.

35. Kosol S, Schmidt J, Kurmayer R. Variation in peptide net production and growth among strains of the toxic cyanobacterium Planktothrix spp. Eur J Phycol. 2009;44(1):49-62.

36. Ellis RJ, Lilley AK, Lacey SJ, Murrell D, Godfray HCJ. Frequency-dependent advantages of plasmid carriage by Pseudomonas in homogeneous and spatially structured environments. ISME J. 2007;1 (1):92-5.

37. Rohrlack T, Christiansen G, Kurmayer R. Putative antiparasite defensive system involving ribosomal and nonribosomal oligopeptides in cyanobacteria of the genus Planktothrix. Appl Environ Microbiol. 2013;79(8): 2642-7.

38. Merrick M, Filser M, Dixon R, Elmerich C, Sibold L, Houmard J. The use of translocatable genetic elements to construct a fine-structure map of the Klebsiella pneumoniae nitrogen-fixation (nif) gene cluster. J Gen Microbiol. 1980;117(APR):509-20

39. Vasas G, Farkas O, Borics G, Felfoldi T, Sramko G, Batta G, et al. Appearance of Planktothrix rubescens bloom with D-Asp ${ }^{3}$, Mdha $^{7}$ MC- RR in gravel pit pond of a shallow lake-dominated area. Toxins. 2013:5(12):2434-55.

40. Rippka R. Isolation and purification of cyanobacteria. Meth Enzymol. 1988; 167:3-27.

\section{Submit your next manuscript to BioMed Central} and we will help you at every step:

- We accept pre-submission inquiries

- Our selector tool helps you to find the most relevant journal

- We provide round the clock customer support

- Convenient online submission

- Thorough peer review

- Inclusion in PubMed and all major indexing services

- Maximum visibility for your research

Submit your manuscript at www.biomedcentral.com/submit

) Biomed Central 